\title{
Short-term inpatient-based high-intensive pulmonary rehabilitation for lung cancer patients: is it feasible and effective?
}

\author{
Kun Zhou ${ }^{1 *}$, Jianhua Su ${ }^{2 *}$, Yutian Lai ${ }^{1 *}$, Pengfei Li ${ }^{1}$, Shuangjiang Li $^{1}$, Guowei Che ${ }^{1}$ \\ ${ }^{1}$ Department of Thoracic Surgery, West China Hospital, Sichuan University, Chengdu 610041, China; ${ }^{2}$ Rehabilitation Department, West China \\ Hospital, Sichuan University, Chengdu 610041, China \\ Contributions: (I) Conception and design: K Zhou, J Su, Y Lai; (II) Administrative support: None; (III) Provision of study materials or patients: \\ None; (IV) Collection and assembly of data: P Li, Y Lai; (V) Data analysis and interpretation: S Li; (VI) Manuscript writing: All authors; (VII) Final \\ approval of manuscript: All authors. \\ *These authors contributed equally to this work. \\ Correspondence to: Guowei Che. Department of Thoracic Surgery, West China Hospital, Sichuan University, Guoxuexiang No. 37, Chengdu 610041, \\ China. Email: guowei_che@yahoo.com.
}

Background: This study was conducted to develop a preoperative in-hospital short-term rehabilitation program for surgical lung cancer patients, and investigate its feasibility, potential cost benefit and effectiveness on outcome measures including reduction of postoperative pulmonary complications (PPCs) and postoperative length of stay.

Methods: A 7-day inpatient-based high-intensive rehabilitation regimen was performed between March 01, 2014 and June 30, 2015. It was combined with inspiratory muscles training (IMT) and aerobic endurance training and was tested in an enriched cohort study with 939 lung cancer patients undergoing lobectomy in a regional thoracic unit.

Results: Finally, 939 patients were divided into pulmonary rehabilitation (PR) group (n=197) and nonPR (NPR) group ( $\mathrm{n}=742)$, according to whether they received the 7-day preoperative in-hospital systematic rehabilitation. The PR group had a shorter total length of stay $(14.7 \pm 4.0$ vs. $16.7 \pm 6.2$ days, $\mathrm{P}<0.001)$ as well as postoperative length of stay $(6.2 \pm 3.3$ vs. $8.3 \pm 5.6$ days, $\mathrm{P}<0.001)$ than the NPR group. Lower incidences of total PPCs (18.3\%, 36/197 vs. 26.1\%, 194/742, P=0.022), pneumonia (11.2\%, 22/197 vs. 17.3\%, 128/742, $\mathrm{P}=0.024)$ and atelectasis $(6.6 \%, 13 / 197$ vs. $12.3 \%, 91 / 742, \mathrm{P}=0.038)$ were found in the $\mathrm{PR}$ group compared with NPR group. Meanwhile, a multivariable analysis of risk to PPCs, atelectasis and pneumonia, revealed that the PR intervention was the independent risk factor of the occurrence of the PPCs (OR $=0.57,95 \% \mathrm{CI}$ : 0.47 to $0.93, \mathrm{P}=0.033$ ) and atelectasis ( $\mathrm{OR}=0.49,95 \% \mathrm{CI}$ : 0.26 to $0.91, \mathrm{P}=0.024$ ).

Conclusions: The study showed the effectiveness of this systematic and high-intensive PR combining IMT and aerobic exercise in reductions of the length of stay and occurrence of PPCs without increase in in-hospital cost, suggesting the potential of this rehabilitation pattern as a practicable strategy performed preoperatively in surgical lung cancer patients.

Keywords: Pulmonary rehabilitation (PR); cost-benefit analysis; lung cancer; lobectomy

Submitted Jul 09, 2017. Accepted for publication Oct 13, 2017.

doi: $10.21037 /$ jtd.2017.10.105

View this article at: http://dx.doi.org/10.21037/jtd.2017.10.105 


\section{Introduction}

Malignant tumors have been the most health-threatening and death-causing disease to humans with the morbidity rate of lung cancer ranking first among all tumors in China since about 600,000 people were attacked in 2010 and 480,000 of them died $(1,2)$. Lung cancer continues to be a difficult disease with a high mortality and symptom burden, in part because of frequent lung comorbidities, even the survivors often remain symptomatically and functionally limited. Surgery is the optimal treatment of early-stage lung cancer, when the pre-malignant or early lesions are amenable to resection and cure $(3,4)$. Postoperative pulmonary complications (PPCs) are the leading cause of morbidity and mortality after lung resection surgery for lung cancer patients, let alone the burden of PPC on the patients (5). Thus, any intervention to reduce PPCs will have a valuable impact on clinical and cost-effectiveness outcomes.

In the last several decades, exercise and physical activity have arisen rapidly as therapeutic options for obstructive lung disease and lung cancer. To date, exercise has shown effectiveness to relieve symptoms, increase exercise tolerance, improve quality of life, and potentially reduce length of stay and postoperative complications, as growing evidence supports activity's benefit in primary and secondary cancer prevention (6). However, the lack of evidence-based consensus as to how and when to implement the pulmonary rehabilitation (PR) regimen has aroused numerous researches focusing on it (7).

Based on this, we performed a study to develop, refine and examine the feasibility of a systemic-intensive preoperative rehabilitation combined with inspiratory muscle training (IMT) and endurance exercise, which may play an impactful role on improving cardiopulmonary intolerance and the sequential reduction of PPC rate.

\section{Methods}

\section{Study subjects and grouping}

We retrospectively collected 939 surgical patients with lung cancer between the year between March 1, 2014 and June 30,2015 , following the inclusion/exclusion criteria listed below. Inclusive criteria: patients who (I) were diagnosed as primary non-small cell lung cancer (NSCLC); (II) with age $\geq 50$ years old; (III) received lung cancer lobectomy ultimately. Exclusive criteria: (I) not primary NSCLC pathologically; (II) did not undergo lobectomy, including sub-lobectomy, pneumonectomy, etc.; (III) received preoperative chemoradiotherapy.

Patients were divided into PR group and non-PR group, according to whether they received the 7-day preoperative in-hospital systematic rehabilitation. Inclusive criteria for rehabilitation included a $\geq 20$ pack-year smoking history, body mass index $\geq 28$, forced expiratory volume in $1 \mathrm{~s}$ percentage $\left(\mathrm{FEV}_{1} \%\right) \leq 60 \%$, chronic obstructive pulmonary disease (COPD), asthma or airway hyper reactivity, which were considered as risk factors of the occurrence of PPCs. Patients were excluded if they had any of the following exclusion criteria: (I) refusal to participate; (II) contraindications for the physical rehabilitation including myocardial infarction or cerebrovascular accident $(<1$ year), unstable angina pectoris, aneurysm, haemoptysis $(<90 \mathrm{~d})$, musculoskeletal or mental disorders. Finally, we enrolled 294 patients into rehabilitation regimen, 65 patients met exclusion criteria, 32 patients refused to participate in regimen and 37 did not complete.

\section{Preoperative PR program}

\section{Education}

Lung cancer nurse specialists performed the education cessions for the participants, including teaching the normative inhalation exercise and abdominal exercise, supervising them to completing the daily exercise cessions in ward, and sequentially making records. Physiotherapists trained and supervised the patients to perform the daily endurance exercise in the rehabilitation training center.

\section{Rehabilitation regimen}

\section{IMT exercise}

IMT exercise was performed in the in-patient ward, including: (I) abdominal breathing training: diaphragm muscles could be strengthened through this exercise (twice a day, with 15-20 minutes each turn). The patient inhaled slowly to the maximum lung capacity through nose, and held the breath for a short time, then exhaled slowly through tips with his abdominal muscles tighten; (II) inspiration exercise: a simple respiratory training device (Voldyne 2500, Sherwood Medical Supplies, St Louis, MO, USA) was used for the training. The patient was guided to exhale calmly at beginning, and then deeply inhaled through the suction nozzle in the training device, and after holding for several seconds, then exhaled slowly. Training pattern lasted three times a day, 20-minute each turn. 


\section{Aerobic endurance training}

The device Nu-Step (Inc. Ann Arbor, Michigan, USA) was used in rehabilitation training center. The patients adjusted the resistance gear range according to their own speed and power at first, and then increased the resistance range progressively. During the training, procedure must be stopped if patients had any obvious discomfort, such as shortness of breath, dyspnea or exhaustion. Patients were allowed to have a rest until his/her condition can withstand the subsequent training. This pattern lasted 30 mins daily.

\section{Rehabilitation expense}

During the rehabilitation regimen, the patients were charged for $\$ 28$, consisting of $\$ 8$ for daily special nursing care and $¥ 20$ for Nustep exercise. This charging standard was established and approved by the hospital and provincial health bureau in 2013.

\section{Data collection}

This study was a retrospective and single-center study of consecutive patients underwent lung cancer lobectomy at the Department of Thoracic Surgery of West China Hospital of Sichuan University between March 1, 2014 and June 30, 2015. The ethics committee gave its approval (number: 2015-176) for the publication of this study with a waiver of informed consent. Clinical data were collected by well-trained coordinators using a hospital database.

\section{Statistical analysis}

Demographic data were presented as follows: continuous variables as mean and standard deviation (mean $\pm \mathrm{SD}$ ), binary variables as frequencies and proportions. The continuous variables were compared by Student's $t$-test, and discrete variables were analyzed using the Chisquare test or Fisher exact test. A multivariable analysis of risk factors of PPCs, pneumonia and atelectasis were analyzed, using the binary logistic regression, variables analyzed included age, gender, smoking status, COPD, diabetes, hypertension or/and coronary disease, early tumor stage (stage I), surgical approach, operation time, amount of bleeding during the operation, $\mathrm{FEV}_{1}$, postoperative predicted $\mathrm{FEV}_{1} \%$ (ppoFEV ${ }_{1} \%$ ), Dlco, postoperative predicted Dlco\% (ppoDlco\%), whether rehabilitation or not. All results were considered significant at $\mathrm{P}<0.05$. Statistical analyses were performed using SPSS software V.21.0 (SPSS Inc., Chicago, IL, USA).

\section{Primary endpoints}

The occurrence of PPCs was the main endpoint of the study. The PPCs in 30 days were identified and recorded. PPCs included (I) pneumonia; (II) prolonged air leak ( $\geq 7$ days); (III) atelectasis; (IV) pleural effusion requiring drainage; (V) acute respiratory distress syndrome (ARDS); (VI) respiratory failure; (VII) mechanical ventilation $\geq 48$ hours postoperatively; (VIII) pulmonary embolism; (IX) empyema. Pneumonia is defined as at least 3 of the following: leukocytosis $>12,000 / \mathrm{mm}^{3}$ or $<3,000 / \mathrm{mm}^{3}$, temperature $>38^{\circ} \mathrm{C}$, purulent sputum, persistent infiltrate on chest roentgenogram, or pathogenic microorganisms from endotracheal aspirate. Also, we used Clavien-Dindo complication classification system to analyze the PPCs, and the PPCs reaching Clavien-Dindo grade II-V were included in final analysis (8).

\section{Results}

\section{Completion status}

Patients $(\mathrm{n}=939)$ (mean age: $58.7 \pm 9.4$ years; range, 50-87 years) were divided into PR group ( $\mathrm{n}=197)$ and nonPR group ( $\mathrm{n}=742$ ), according to whether they performed the 7-day preoperative in-hospital systematic rehabilitation. There was no significant difference between the groups in their preoperative characteristics, and the baseline data were listed in Table 1. Regarding to the duration of rehabilitation regimen, $17(8.6 \%, 17 / 197)$ in the PR group perform the PR program for $1-3$ days, $20(10.2 \%, 20 / 197)$ for 4-6 days, and $160(81.2 \%, 160 / 197)$ completed the regimen. Among the 197 patients who agreed and finally participated in the rehabilitation regimen, $37(18.8 \%, 37 / 197)$ did not completed the 7 -day rehabilitation plan due to various reasons: $7(18.9 \%, 7 / 37)$ required for advancing the surgery, $9(24.3 \%, 9 / 37)$ perceived lack of benefit, $11(29.7 \%, 11 / 37)$ could not endure the high-intensive regimen, 7 (18.9\%, 7/37) considered time/expense cost and suspended, and 3 $(8.1 \%, 3 / 37)$ for other reasons (Table 2).

\section{Clinical characteristics}

The PR group had a shorter total length of stay $(14.7 \pm 4.0$ vs. $16.7 \pm 6.2$ days, $\mathrm{P}<0.001)$ as well as postoperative length of stay $(6.2 \pm 3.3 v s .8 .3 \pm 5.6$ days, $\mathrm{P}<0.001)$ than the NPR group. However, no difference was found in the preoperative inhospital stay $(8.6 \pm 1.9$ vs. $8.4 \pm 1.8$ days, $\mathrm{P}=0.230)$ between the groups. The details can be seen in Table 2 . 
Table 1 Baseline of the two groups

\begin{tabular}{|c|c|c|c|}
\hline Characteristics & $\begin{array}{l}\text { PR group, } \\
n=197\end{array}$ & $\begin{array}{l}\text { NPR group, } \\
n=742\end{array}$ & $P$ \\
\hline Age, mean \pm SD & $58.5 \pm 9.6$ & $58.8 \pm 9.3$ & 0.564 \\
\hline \multicolumn{4}{|l|}{ Gender } \\
\hline Men & $116(58.9)$ & $406(54.7)$ & 0.295 \\
\hline $\mathrm{FEV}_{1}, \mathrm{~L}$ & $2.2 \pm 0.6$ & $2.3 \pm 0.5$ & 0.059 \\
\hline ppoFEV $_{1} \%$ & $69.9 \pm 17.5$ & $69.3 \pm 18.4$ & 0.676 \\
\hline Dlco, $\mathrm{mL} / \mathrm{min} / \mathrm{mmHg}$ & $21.7 \pm 5.0$ & $22.2 \pm 5.0$ & 0.231 \\
\hline ppoDlco\% & $72.2 \pm 23.3$ & $71.4 \pm 24.6$ & 0.684 \\
\hline \multicolumn{4}{|l|}{ Comorbidities } \\
\hline $\begin{array}{l}\text { Hypertension or/and } \\
\text { coronary disease }\end{array}$ & $10(5.0)$ & $37(5.0)$ & 0.959 \\
\hline Current smoking status & $50(25.4)$ & $176(23.7)$ & 0.628 \\
\hline COPD & $22(11.2)$ & $92(12.4)$ & 0.638 \\
\hline Diabetes & $13(6.6)$ & $49(6.6)$ & 0.998 \\
\hline Clinical stage & & & 0.524 \\
\hline Stage I & $102(51.8)$ & $350(47.2)$ & \\
\hline Stage II & $69(35.0)$ & $303(40.8)$ & \\
\hline Stage III & $24(12.2)$ & 81 (10.9) & \\
\hline Stage IV & $2(1.0)$ & $8(1.1)$ & \\
\hline \multicolumn{4}{|l|}{ Surgical approach } \\
\hline VATS & $122(61.9)$ & 489 (65.9) & 0.298 \\
\hline Open & $75(38.1)$ & $253(34.1)$ & \\
\hline Duration of drainage & $4.2 \pm 2.8$ & $4.5 \pm 2.5$ & 0.110 \\
\hline $\begin{array}{l}\text { Average time of in-hospital } \\
\text { stay, day }\end{array}$ & $14.7 \pm 4.0$ & $16.7 \pm 6.2$ & $<0.001$ \\
\hline Preoperative, day & $8.6 \pm 1.9$ & $8.4 \pm 1.8$ & 0.230 \\
\hline Postoperative, day & $6.2 \pm 3.3$ & $8.3 \pm 5.6$ & $<0.001$ \\
\hline
\end{tabular}

Data are shown as number (\%) or mean \pm standard deviation. PR, pulmonary rehabilitation; NPR, non-pulmonary rehabilitation; $\mathrm{FEV}_{1}$, forced expiratory volume in one second; ppoFEV1, postoperative predicted $\mathrm{FEV}_{1}$. Dlco, diffusion capacity for carbon monoxide of the lung; COPD, chronic obstructive pulmonary disease; VATS, video assisted thoracic surgery.

The PR group spent average $\$ 142$ for the rehabilitation regimen, and had a higher preoperative cost compared with NPR group $(\$ 579.2 \pm \$ 211.5$ vs. $\$ 438.6 \pm \$ 206.3, \mathrm{P}<0.001)$. But no significantly difference was found in the average inhospital cost between the two groups $(\$ 7,131.8 \pm \$ 2,316.6$ vs. $\$ 7,266.4 \pm \$ 1,615.0, \mathrm{P}=0.347)$. Respectively, the postoperative
Table 2 Rehabilitation regimen and completion status

\begin{tabular}{|c|c|}
\hline Variables & Exercise intervention \\
\hline \multicolumn{2}{|l|}{ Components } \\
\hline \multirow[t]{2}{*}{ IMT } & $\begin{array}{l}\text { Abdominal exercise: } 20 \text { breaths/ } \\
\text { cession, } 3 \text { times a day for } 7 \text { days }\end{array}$ \\
\hline & $\begin{array}{l}\text { Inhalation exercise (spirometer): } \\
20 \text { min/cession, } 3 \text { times a day for } \\
7 \text { days }\end{array}$ \\
\hline Endurance exercise & Nustep: 30 min, once a day for 7 days \\
\hline \multirow[t]{3}{*}{ Completion status } & 1 3 days: 17 (8.6) \\
\hline & 4 6 days: 20 (10.2) \\
\hline & Completing: 160 (8.2) \\
\hline \multicolumn{2}{|l|}{$\begin{array}{l}\text { Reasons for not } \\
\text { completing the regimen } \\
(n=37)\end{array}$} \\
\hline \multicolumn{2}{|c|}{$\begin{array}{l}\text { Requiring for advancing } 7 \text { (18.9) } \\
\text { the surgery }\end{array}$} \\
\hline $\begin{array}{l}\text { Perceived lack of } \\
\text { benefit }\end{array}$ & $9(24.3)$ \\
\hline $\begin{array}{l}\text { Could not endure the } \\
\text { high-intensive regimen }\end{array}$ & $11(29.7)$ \\
\hline $\begin{array}{l}\text { Consideration of time/ } \\
\text { expense cost }\end{array}$ & 7 (18.9) \\
\hline Other reasons & $3(8.1)$ \\
\hline
\end{tabular}

expense ( $\mathrm{P}=0.001)$, post-ward cost $(\mathrm{P}=0.001)$, post-care cost $(\mathrm{P}=0.001)$, post-drug cost $(\mathrm{P}=0.004)$ in the $\mathrm{PR}$ group were significantly lower than in the NPR group (Table 3).

\section{PPC rate}

Pneumonia (14.9\%, 140/939), atelectasis needing bronchoscope $(11.1 \%, 104 / 939)$ and air leak $\geq 7$ days $(8.3 \%$, 78/939) were the leading PPCs presented after the surgery in 30 days. Lower incidences of total PPCs $(18.3 \%, 36 / 197$ vs. $26.1 \%, 194 / 742, \mathrm{P}=0.022)$, pneumonia $(11.2 \%, 22 / 197$ vs. $17.3 \%, 128 / 742, \mathrm{P}=0.024)$ and atelectasis $(6.6 \%, 13 / 197$ vs. $12.3 \%, 91 / 742, \mathrm{P}=0.038$ ) were found in the $\mathrm{PR}$ group, compared with in NPR group (Table 4).

Furthermore, we performed a multivariable analysis of risk to PPCs, pneumonia and atelectasis with variables including age, gender, smoking status, COPD, diabetes, hypertension or/and coronary disease, early tumor stage (stage I), surgical approach, operation time, amount 
Table 3 In-hospital expense between the groups

\begin{tabular}{lccc}
\hline Variables & PR group $(\$)$ & NPR group $(\$)$ & P \\
\hline Total expense & $7,131.8 \pm 2,316.6$ & $7,266.4 \pm 1,615.0$ & 0.347 \\
Preoperative costs & $579.2 \pm 211.5$ & $438.6 \pm 206.3$ & $<0.001$ \\
Ward expense & $118.4 \pm 34.7$ & $115.3 \pm 32.0$ & 0.236 \\
Care expense & $53.3 \pm 15.6$ & $51.9 \pm 14.4$ & 0.234 \\
Rehabilitation & $142.0 \pm 32.5$ & 0 & $<0.001$ \\
expense & & & \\
Surgery related & $5,602.5 \pm 2,211.1$ & $5,751.0 \pm 1,495.5$ & 0.270 \\
expense & & & \\
Postoperative costs & $949.3 \pm 462.6$ & $1,076.8 \pm 524.9$ & 0.001 \\
Drug expense & $379.1 \pm 211.3$ & $444.8 \pm 201.0$ & 0.004 \\
Ward expense & $112.0 \pm 57.0$ & $131.0 \pm 100.4$ & 0.001 \\
Care expense & $67.2 \pm 35.9$ & $78.6 \pm 60.2$ & 0.001 \\
\hline
\end{tabular}

PR, pulmonary rehabilitation; NPR, non-pulmonary rehabilitation.

of bleeding during the operation, $\mathrm{FEV}_{1}$, $\operatorname{ppoFEV}_{1} \%$, Dlco, ppoDlco\%, whether rehabilitation or not. The PR intervention $(\mathrm{OR}=0.57,95 \% \mathrm{CI}: 0.47$ to $0.93, \mathrm{P}=0.033)$ and operation time (OR $=1.01,95 \% \mathrm{CI}: 1.00$ to $1.02, \mathrm{P}=0.043$ ) were the independent risk factors to the occurrence of PPCs. Meanwhile, $\mathrm{FEV}_{1}$ (OR =2.93, 95\% CI: 1.12 to 7.68; $\mathrm{P}=0.029)$ value was the independent factor for pneumonia, and the PR intervention ( $\mathrm{OR}=0.49,95 \% \mathrm{CI}: 0.26$ to 0.91 , $\mathrm{P}=0.024)$, early tumor stage $(\mathrm{OR}=0.58,95 \% \mathrm{CI}: 0.37$ to $0.89, \mathrm{P}=0.014)$ and $\mathrm{COPD}(\mathrm{OR}=2.22,95 \% \mathrm{CI}: 1.16$ to 4.25 , $\mathrm{P}=0.016)$ for atelectasis (Table 5).

\section{Discussion}

This study developed and refined a preoperative short-term and integrated rehabilitation program combining IMT with endurance exercise, and validated its effectiveness on reducing PPCs rate as well as in-hospital stay, on the premise of not increasing the in-hospital expense, and all with the primary aim of optimizing and enhancing recovery and physical status of patients undergoing curative lung cancer surgery. Compared with rehabilitation at home, the adherence of this in-hospital PR pattern might be higher, under the guidance and supervision of the trained nurses and physiotherapists. Unlike other researches mainly aiming at the effectiveness of IMT for lung cancer patients (9-11), this main intervention treatment in this study was a modified preoperative PR program combining with IMT and aerobic endurance
Table 4 PPCs rate in 30 days between the PR and NPR groups

\begin{tabular}{lccc}
\hline Outcome variables & $\begin{array}{c}\text { PR group, } \\
\mathrm{n}=197\end{array}$ & $\begin{array}{c}\text { NPR group, } \\
\mathrm{n}=742\end{array}$ & $\mathrm{P}$ \\
\hline PPCs rate & $36(18.3)$ & $194(26.1)$ & 0.022 \\
Grade II & & & \\
Pneumonia & $22(11.2)$ & $128(17.3)$ & 0.024 \\
Atelectasis needing & $13(6.6)$ & $91(12.3)$ & 0.038 \\
bronchoscope & & & \\
Air leak $\geq 7$ days & $16(8.1)$ & $62(8.4)$ & 0.916 \\
$\begin{array}{l}\text { Pleural effusion needing } \\
\text { drainage }\end{array}$ & $14(7.1)$ & $49(6.6)$ & 0.802 \\
Grade III & & & \\
Bronchopleural fistula & $4(2.0)$ & $13(1.8)$ & 0.766 \\
Mechanical ventilation & $8(4.1)$ & $27(3.6)$ & 0.781 \\
$>48 \mathrm{~h}$ & & & \\
Empyema & $6(3.0)$ & $30(4.0)$ & 0.517 \\
Grade IV & & & \\
$\begin{array}{l}\text { Respiratory failure or } \\
\text { ARDS }\end{array}$ & $4(2.0)$ & $8(1.1)$ & 0.289 \\
$\begin{array}{l}\text { Pulmonary embolism } \\
\text { Back to ICU }\end{array}$ & $2(1.0)$ & $5(0.7)$ & 0.922 \\
Grade V & $4(2.0)$ & $7(0.9)$ & 0.256 \\
\hline Death & & & 0.611 \\
\hline
\end{tabular}

Data are shown as number (\%). PPCs rate was defined as PPCs with Clavien-Dindo grade over level II (grade II-V). PPCs, postoperative pulmonary complications; PR, pulmonary rehabilitation; NPR, non-pulmonary rehabilitation; ARDS, acute respiratory distress syndrome; ICU, intensive care unit.

training. Inspiratory training has a long history of research, especially among patients with COPD, asthma, or poor lung function. It has been proven effective for improving inspiratory muscle strength and endurance, functional exercise capacity and dyspnea symptoms $(12,13)$. In addition, the aerobic endurance training under the guidance of physical therapist, is consider as a safe and effective strategy aiming at tumor patients (14).The American Cancer Society recommends that adults with cancer engage in at least 150 minutes of moderate-intensity aerobic exercise and two sessions of resistance exercise per week (15), as they have been proposed as alternative training modality for resistance training on multi-gym equipment, helping to represent the disease severity and clinically relevant exercise-tolerance in pediatric pulmonary arterial hypertension, improving 
Table 5 Multivariable analysis of risk to PPCs, pneumonia and atelectasis*

\begin{tabular}{lccc}
\hline $\begin{array}{l}\text { PPC } \\
\text { categories }\end{array}$ & Variables & OR $(95 \% \mathrm{Cl})$ & $\mathrm{P}$ \\
\hline PPCs & PR intervention & $0.57(0.47-0.93)$ & 0.033 \\
& Operation time & $1.01(1.00-1.02)$ & 0.043 \\
Pneumonia & FEV value & $2.93(1.12-7.68)$ & 0.029 \\
& PR intervention & $0.62(0.38-1.02)$ & 0.061 \\
Atelectasis & PR intervention & $0.49(0.26-0.91)$ & 0.024 \\
& CoPD & $2.22(1.16-4.25)$ & 0.016 \\
& Early tumor stage & $0.58(0.37-0.89)$ & 0.014 \\
\hline
\end{tabular}

*, variables analyzed included age, gender, smoking status, COPD, diabetes, hypertension or/and coronary disease, early tumor stage (stage I), surgical approach (open/VATS), operation time, amount of bleeding during the operation, $\mathrm{FEV}_{1}$, ppoFEV $1 \%$, Dlco, ppoDIco\%, whether rehabilitation or not. PPCs, postoperative pulmonary complications; PR, pulmonary rehabilitation; $\mathrm{FEV}_{1}$, forced expiratory volume in one second; COPD, chronic obstructive pulmonary disease.

cardiopulmonary coordination ability, as well as exercise tolerance (16-18). We hypothesized that a shorter-term intensive treatment combining IMT with aerobic endurance training to lung cancer patients could be a better strategy compared with conventional care.

The duration of the PR vary with the range from 3 days to 12 weeks in different studies $(9,19,20)$. In China, a short in-hospital PR regimen is considered to be a more feasible and appropriate, for the deficiencies in basic-level hospitals and the primary care system make it infeasible and impracticable for patients to rehabilitate either at home or in community hospitals. Also, lung cancer patients generally spend 7-10 days preparing for surgery in China, including completing the diagnosis process, finishing surgery-related examinations, because of the inadequate equipment and technical skills in basic institutions. Considering that the length of the regimen to fit with cancer waiting time targets and surgery should not be delayed due to the program, one-week time is a time plot that could be accepted before operations as a longer duration maybe weaken the patientcompliance. Hence, with our previous experience, we set a unified duration of 7-day intensive PR for all PR group patients as this appropriate duration may achieve the efficiency of PR, and also balance the contradiction of patient-compliance as well as patient-economic-support. According to the results, $81.2 \%$ participants finally completed the 7-day regimen, suggesting the favorable compliance of the patients and the feasibility of this PR pattern. Additionally, we recorded the reasons why the patients did not complete the PR regimen: among the 37 who did not finish the regimen, $29.7 \%$ of them could not endure the high-intensive regimen, which also indicated the practicability of this regimen, though further prospective research is currently needed to confirm the view.

We wished that the $\mathrm{PR}$ program was sustainable in the current cost-sensitive era, as a cost-effective strategy for the lung cancer patients. The results revealed that there was no increased expenditure in the total in-hospital cost in the PR group compared with the routine group, though the PR group expensed $\$ 142$ for the regimen. Moreover, a significant reduced postoperative expense as well as drug, ward, care cost was observed. These economic findings suggested that this rehabilitation model did not increase the economic burden to the participants. Potential explanations for these findings may include fewer PPCs and sequentially better postoperative recovery occurred in the intervention group, which led to shorter postoperative hospital stay, reduced use of medication and medical care and, consequently, lower in-hospital expenses.

Another essential issue was PPCs rate. PPCs significantly contribute to overall perioperative morbidity and mortality rates. However, whether the PR can reduce the rate of PPCs is still unclear (6,20-23), with controversies including exercise duration, suitable or optimal scheduling and content of the exercise. Our results revealed lower occurrences of PPCs, pneumonia and atelectasis, suggesting the effectiveness of this rehabilitation pattern in reducing the PPCs rate. Moreover, the multivariable analysis of risk revealed the $\mathrm{PR}$ intervention as independent risk factor for the occurrence of PPCs and atelectasis, providing meaningful evidence of the effectiveness, though for pneumonia, the intervention was not the independent risk factor. Due to the 7-day highintensive and normative IMT and endurance exercises, the cardiopulmonary endurance of the participants would be enhanced, which might better tolerate the surgery and present better postoperative status or outcomes. Also, shorter average post- length of stay and expense were found in the PR group, revealing the physical and economic benefits the regimen provided for the patients.

This study may be brought to the forefront of further studies regarding the PR program as the concept of enhancing the patients' physical and respiratory health prior to lung surgery is vitally important to the patients. However, 
some limitations exist which are inevitably ignored, as this is a retrospective cohort study with all the subjects from a single medical center. Firstly, as this was an exploratory study, we mainly selected risk factors based on the National Expert Consensus and Guidelines for Thoracic Surgery (2012) and a combination of literature review and empiric analysis. Secondly, this rehabilitation regimen did have some contraindications, including myocardial infarction or cerebrovascular accident within 1 year, unstable angina pectoris, aneurysm, recent history ( $<90$ days) of hemoptysis, high risk of severe arrhythmia, musculoskeletal or mental disorders, which meant that the population with these contraindications was not included in the PR group. Hence, it was difficult to discuss the impact of this difference between the groups, which may limit the generalization of the conclusions. Thirdly, baseline $\mathrm{FEV}_{1}$ parameter presented a marginally statistical significant difference $(\mathrm{P}=0.059)$ between $\mathrm{PR}$ and NPR groups. The reasons of this tendency may be that patients with poorer lung function would more likely to participant in the PR regimen as they might be more interest in the benefit from the PR. This bias may confound the results, and further affect the conclusion. Fourth, with regard to in-hospital expense, we did not specially analyze the PPC-related cost, which might be more convictive to suggest the cost-effectiveness of this PR program. In addition, we merely collected the data of PPCs after surgery in 30 days, without their long-term outcome. Furthermore, to better evaluate the effectiveness of the program in the enhancement of cardiopulmonary endurance, some instruments, for example, 6 min walk test or CPET (cardiopulmonary exercise test) should be used in our further study.

\section{Acknowledgements}

The authors thank all the personal trainers and physiotherapists for their work during the study process, Dr. $\mathrm{H}$ Zhou for patient recruitment, nurses $\mathrm{D} \mathrm{Ma}, \mathrm{Z} \mathrm{Xu}$ and $\mathrm{J}$ Chen for nursing care support. Meanwhile, we also thank all the participants for their kind participation and cooperation. Funding: This study was supported by Foundation of Science and Technology support plan. Department of Sichuan Province (No.2015SZ0158).

\section{Footnote}

Conflicts of Interest: The authors have no conflicts of interest to declare.
Ethical Statement: The ethics committee gave its approval (number: 2015-176) for the publication of this study with a waiver of informed consent.

\section{References}

1. Vansteenkiste J, Dooms C, Mascaux C, et al. Screening and early detection of lung cancer. Ann Oncol 2012;23 Suppl 10:x320-7.

2. Zheng R, Zeng H, Zhang S, et al. Lung cancer incidence and mortality in China, 2010. Thorac Cancer 2014;5:330-6.

3. Boffa DJ, Allen MS, Grab JD, et al. Data from The Society of Thoracic Surgeons General Thoracic Surgery database: the surgical management of primary lung tumors. J Thorac Cardiovasc Surg 2008;135:247-54.

4. Jazieh AR, Kyasa MJ, Sethuraman G, et al. Disparities in surgical resection of early-stage non-small cell lung cancer. J Thorac Cardiovasc Surg 2002;123:1173-6.

5. Agostini P, Cieslik H, Rathinam S, et al. Postoperative pulmonary complications following thoracic surgery: are there any modifiable risk factors? Thorax 2010;65:815-8.

6. Bade BC, Thomas DD, Scott JB, et al. Increasing physical activity and exercise in lung cancer: reviewing safety, benefits, and application. J Thorac Oncol 2015;10:861-71.

7. Crandall K, Maguire R, Campbell A, et al. Exercise intervention for patients surgically treated for non-small cell lung cancer (NSCLC): a systematic review. Surg Oncol 2014;23:17-30.

8. Dindo D, Demartines N, Clavien PA. Classification of Surgical Complications: a new proposal with evaluation in a cohort of 6336 patients and results of a survey. Ann Surg 2004;240:205-13.

9. Benzo R, Wigle D, Novotny P, et al. Preoperative pulmonary rehabilitation before lung cancer resection: results from two randomized studies. Lung Cancer 2011;74:441-5.

10. Yamana I, Takeno S, Hashimoto T, et al. Randomized controlled study to evaluate the efficacy of a preoperative respiratory rehabilitation program to prevent postoperative pulmonary complications after esophagectomy. Dig Surg 2015;32:331-7.

11. Stefanelli F, Meoli I, Cobuccio R, et al. High-intensity training and cardiopulmonary exercise testing in patients with chronic obstructive pulmonary disease and nonsmall-cell lung cancer undergoing lobectomy. Eur J Cardiothorac Surg 2013;44:e260-5.

12. Gosselink R, De Vos J, van den Heuvel SP, et al. Impact of 
inspiratory muscle training in patients with COPD: what is the evidence? Eur Respir J 2011;37:416-25.

13. Weiner $P$, Weiner M. Inspiratory muscle training may increase peak inspiratory flow in chronic obstructive pulmonary disease. Respiration 2006;73:151-6.

14. Granger CL. Physiotherapy management of lung cancer. J Physiother 2016;62:60-7.

15. Rock CL, Doyle C, Demark-Wahnefried W, et al. Nutrition and physical activity guidelines for cancer survivors. CA Cancer J Clin 2012;62:243-74.

16. Rittweger J, Beller G, Felsenberg D. Acute physiological effects of exhaustive whole-body vibration exercise in man. Clin Physiol 2000;20:134-42.

17. Van Erck A, Vanden Bossche L, Witvrouw E, et al. Effect of whole body vibration on intracompartmental pressure in the lower leg. J Orthop Sci 2009;14:618-22.

18. Salhi B, Haenebalcke C, Perez-Bogerd S, et al. Rehabilitation in patients with radically treated respiratory cancer: A randomised controlled trial comparing two

Cite this article as: Zhou K, Su J, Lai Y, Li P, Li S, Che G. Short-term inpatient-based high-intensive pulmonary rehabilitation for lung cancer patients: is it feasible and effective? J Thorac Dis 2017;9(11):4486-4493. doi: 10.21037/ jtd.2017.10.105 training modalities. Lung Cancer 2015;89:167-74.

19. Shiono S, Abiko M, Sato T. Postoperative complications in elderly patients after lung cancer surgery. Interact Cardiovasc Thorac Surg 2013;16:819-23.

20. Rivas-Perez H, Nana-Sinkam P. Integrating pulmonary rehabilitation into the multidisciplinary management of lung cancer: a review. Respir Med 2015;109:437-42.

21. Pehlivan E, Turna A, Gurses A, et al. The effects of preoperative short-term intense physical therapy in lung cancer patients: a randomized controlled trial. Ann Thorac Cardiovasc Surg 2011;17:461-8.

22. Cesario A, Ferri L, Galetta D, et al. Post-operative respiratory rehabilitation after lung resection for nonsmall cell lung cancer. Lung Cancer 2007;57:175-80.

23. Sekine Y, Chiyo M, Iwata T, et al. Perioperative rehabilitation and physiotherapy for lung cancer patients with chronic obstructive pulmonary disease. Jpn J Thorac Cardiovasc Surg 2005;53:237-43. 